\title{
Inventory control applying sales demand prevision based on fuzzy inference system
}

\section{Enyleide Lima Nogueira ${ }^{1}$, Manoel Henrique Reis Nascimento ${ }^{2}$}

\author{
${ }^{1}$ Laureate International Universities (UNINORTE). Av. Djalma Batista, 2100. N. Sra . das Graças, Plaza Shopping. Manaus - AM. \\ ${ }^{2}$ Instituto de Tecnologia e Educação Galileo da Amazônia (ITEGAM) - Av. Joaquim Nabuco, 1950, Centro. Manaus - AM.
}

Email: enyleide.lima@gmail.com.br,hreys@bol.com.br

Received: June $12^{\text {th }}, 2017$

Accepted: September $25^{\text {th }}, 2017$

Published: September $30^{\text {th }}, 2017$

Copyright $\odot 2016$ by authors and Institute of Technology Galileo of Amazon (ITEGAM) This work is licensed under the Creative Commons Attribution International License (CC BY 4.0).

http://creativecommons.org/licenses/by/4.0/

\section{ABSTRACT}

The market scenario of intense changes requires organizations to develop competitive factors, so developing methods for forecasting and controlling inventory is of fundamental importance for the company survival. This paper proposes a demand prevision model with fuzzy inference as a basis for major strategic decisions of the organization, having as variables the marketing mix.

Keywords: Inventory control, Demand Forecasting, Marketing mix, Fuzzy inference.

Controle de estoque aplicando previsão de demanda de vendas baseado no sistema de inferência fuzzy

\section{RESUMO}

O cenário mercadológico de intensas mudanças exige das organizações que desenvolvam fatores competitivos, dessa forma, desenvolver métodos para previsão e controle de estoque é de fundamental importância para a sobrevivência da empresa. O presente artigo propõe um modelo de previsão de demanda com inferência fuzzy como base para as principais decisões estratégicas da organização, tendo como variáveis o composto mercadológico.

Palavras-chave: Controle de estoque, Previsão de demanda, Composto de marketing, Inferência fuzzy.

\section{INTRODUÇÃO}

O contexto mercadológico atual é de rápidas transformações impulsionadas, principalmente, pelo avanço tecnológico que induz as organizações a buscarem diferenciais competitivos. Dado o que se expôs o controle de estoque tende contribuir para que a organização adote novas posturas estratégicas, certificando que se tenha o produto à disposição dos clientes na quantidade correta e na hora exata, evitando maiores investimentos e conferindo melhores resultados e maior competitividade à empresa.

O papel primário do estoque é o de suprir imprecisões na previsão da demanda, incorreções na produção ou no tempo de reposição dos produtos, sendo elencado como um dos principais custos da organização. A existência do estoque se dá devido a diferença de ritmo entre fornecimento e demanda [1].

Como consequência, refrear o estoque resultou em ser uma das maiores preocupações dos gestores em virtude de se evitar rupturas no caixa. O controle de estoque tem sido definido como o conjunto de medidas adotadas para se obter o quantitativo mínimo de estoque possível, sem comprometer o atendimento da demanda, evitando a supressão ou excedente dos produtos oferecidos.

Controlar o estoque diz respeito ao motivo que incitam à tomada de decisões quanto à quantidade de materiais que se deve manter em estoque, considerando critérios econômicos associados aos custos de se manter estoque com a finalidade de gerir os estoques viabilizando a otimização do espaço e melhor informando no tocante as quantidades disponíveis [2].

Prenunciar qual a demanda de vendas da empresa no intuito de se antecipar a compra de produtos junto a seus fornecedores evita estoques prescindíveis ou a indisponibilidade do produto aos clientes, além de ser parte essencial de um bom planejamento. Conhecer as principais variáveis que afetam a demanda de vendas para subsidiar a tomada de decisão é o ponto de partida do processo de planejamento estratégico da organização. 
Dessa forma ferramenta mais cabível que a empresa possui para gerenciamento de estoque é a previsão das necessidades ligadas às vendas, que possibilita um melhor gerenciamento e apuração exata na forma quantitativa dos produtos [3].

Apresentar um modelo de gestão de estoque por intermédio da previsão da demanda de venda que considere as características das novas demandas e que estime os fatores que alteram a produção tem sido um dos maiores desafios da atualidade, visto que as formas mais usuais de previsão de demanda consistem em analisar a média da produção histórica do produto e o cálculo estatístico baseado numa amostra de dados.

Nesse contexto, a utilização de um modelo baseado na inferência fuzzy permite ao gestor que avalie o impacto das suas decisões de maneira a otimizar a lucratividade da empresa, uma vez que a lógica fuzzy tem sido amplamente difundida em questionamento e problemas dos mais diversos como apoio na tomada de decisão em situações de ambiente incerto, uma vez que a lógica fuzzy surgiu como meio de representação e manipulação de dados imprecisos.

O presente artigo tem por objetivo apresentar um modelo de inferência fuzzy para o controle de estoque analisando previsão de demanda de vendas, subsidiando informações precisas para apoio na tomada de decisão.

\section{REVISÃO BIBLIOGRÁFICA}

\section{II.1 CONTROLE DE ESTOQUE}

Os estoques tem a função de regular todo o fluxo dos negócios e estão presentes em todos os processos de uma empresa, respondendo por uma parcela significativa dos custos da organização [4]. Considera-se que o estoque representa uma ferramenta estratégica de fator competitivo que favorece os clientes que necessitam fornecimento imediato ou um curto período de reposição.

Tem-se sabido que mais desafiador que conhecer o estoque de uma empresa não está em minimizar a quantidade de materiais estocados, nem cingir os custos, mas sim obter a quantidade correta de materiais estocada para atender a primazia gerencial de maneira eficaz.

Então, para alavancar sucesso no mercado é necessário se somar um bom atendimento, diversificação de produtos concernente à alta qualidade e uma boa localização, não obstante, na hipótese de uma empresa possuir todos os quesitos supracitados e ainda assim apresentar resultados financeiros insatisfatórios é presumível que boa parte de seu capital esteja repousado no estoque [5].

As medidas adotadas pela administração e gestores para planejar, organizar, dirigir e controlar o estoque é definida pela expressão controle de estoque que se realizada de maneira eficaz outorga o alcance dos objetivos pretendidos pela empresa. Dessarte, para que os resultados na efetivação do controle do estoque sejam satisfatórios é fundamental que o administrador saiba utilizar do espaço para um controle interno satisfatório e eficaz, pautando soluções favoráveis ao melhoramento da gestão com apoio dos colaboradores no desenvolvimento dos procedimentos da empresa.

O controle de estoque tem o papel elementar em todo processo da cadeia produtiva, buscando manter o estoque necessário para se suprir a demanda sem comprometer o capital da empresa com custos excessivos de estoques. A redução racional nos custos correspondentes ao estoque é traduzida em uma maior margem de lucro da empresa [6].
Dada a relevância dos estoques para uma empresa, os gestores devem fadar maior atenção à administração de materiais, posto que essa atividade possui a capacidade de afetar, de forma positiva ou negativa, os resultados da empresa [2].

Seja qual for o método adotado é necessária a observância das rotinas adotadas com a finalidade de evitar problemas de controle, que incidam consequências no inventário, que redundam prejuízos para a empresa. Controle de estoque é o procedimento adotado para registrar, fiscalizar e gerir a entrada e saída de mercadorias e produtos seja na indústria ou comércio [7].

Manter os níveis de estoque em equilíbrio de forma racional visando igualar a demanda aos níveis ideais de estoque vem sendo um dos maiores desafios da administração de estoques. Deste modo, as empresas desejam trabalhar com o mínimo de estoque possível, adotando-se diversas variáveis e critérios para canalizar os investimentos e consequentemente minimizar custos.

Além das vantagens já apresentadas, a boa gestão do controle de estoque contempla a redução e até mesmo abolição de perdas ou roubos de materiais, permite o conhecimento prévio da quantidade de materiais necessário para suprir a demanda futura, faculta a reposição de materiais no momento exato, cessa compras desnecessárias, viabiliza traçar estratégias de compras eficientes e promove aumento na rotatividade dos estoques [8].

\section{II.2 PREVISÃO DE DEMANDA}

Previsão por definição é uma sequência de etapas que o gestor realiza, seja implícita ou não, para prognosticar um valor futuro. Contudo, em virtude das complexidades que envolvem o processo decisório em ambientes organizacionais não estruturados, a tomada de decisão sobre quais etapas adotar tem sido uma árdua tarefa [9].

A melhor ferramenta de gestão de uma empresa na administração de estoques são as previsões de demandas futuras que possibilitam um correto gerenciamento e levantamento exato do quantitativo de produtos, focando principalmente no histórico de saídas dos produtos que corresponde às necessidades futuras dos clientes [3].

Um sistema de previsão de demanda possui quatro etapas operacionais e que incluem a definição do problema, ou seja, qual a variável a ser prevista, a obtenção padrão de demanda (histórico de demanda) e os dados contextuais, a escolha do método de previsão, a implementação do método selecionado e o monitoramento das previsões [10].

A imprecisão é a variável que diligencia maior atenção, podendo reduzir o grau de interferência dela ao se utilizar alguns métodos e os métodos para se estimar a demanda podem ser de natureza qualitativa (baseada em estimativas e/ou opiniões dos gestores) ou quantitativa (baseada em ferramentas estatísticas e de programação, pressupondo o uso de cálculos) [11].

O crescimento ou o declínio das taxas de demanda, sazonalidades e flutuações gerais causadas por diversos fatores resultam nos padrões de demanda[12]. Os padrões de demanda podem ser definidos como irregular ou regular, em que o primeiro ocorre no caso de demanda intermitente ou elevado grau de incerteza a respeito do nível de ocorrência da demanda, sendo classificado como a mais difícil de prever, e o segundo, padrão de demanda regular, é decomposto em cinco componentes, que são a demanda média para o período, tendência, sazonalidade, fatores cíclicos e a variação aleatória.

A classificação dos métodos de previsão é segundo critérios variados, que baseiam-se nos tipos de instrumentos e conceitos que formam a base de previsão, sendo esses métodos baseados em critérios: 
a) Qualitativos (com base em julgamentos) - sendo métodos fundamentados no julgamento de pessoas estejam relacionadas com o processo e tenham condições de opinar sobre a demanda futura, não se apoiam em nenhum modelo específico e são conduzidos de maneira sistemática. Tais métodos são muito utilizados na ausência de dados ou no lançamento de novos produtos.

b) Qualitativos (ou matemáticos) - são métodos que utilizam modelos matemáticos com a finalidade de se chegar aos valores previstos, permitindo controle dos erros, porém, exigem informações quantitativas preliminares, podendo ser métodos causais (em que a demanda de um item é relacionada a um ou mais variáveis internas ou externas à organização); e séries temporais (que são um conjunto de valores de demanda tomados em instantes específicos de tempo com igual intervalo de tempo, em que o padrão observado nos valores passados forneça informações adequadas para a previsão de valores futuros de demanda).

Dessa forma, para se obter uma boa gestão e controle de estoque, a primeira etapa operacional é utilizar de modelos de previsão de demanda, a partir dos quais poderá se conhecer a demanda dos produtos, podendo assim realizar um gerenciamento de estoque mais eficiente, permitindo adquirir somente o necessário para um determinado período.

\section{II.3 O COMPOSTO DE MARKETING}

O mix de marketing se constitui por uma série de atividades, porém, no início dos anos 60, Jerome McCarthy, propôs um mix de markenting que consistia em produto, preço, praça e promoção, sendo definido por 4 P's, onde cada $\mathrm{P}$ abrange outras diversas atividades [13].

Sendo assim, o composto mercadológico ou mix de marketing é formado por várias atividades que têm em vista motivar, impelir e instigar o consumidor a comprar um determinado produto em detrimento de outro.

O conceito de composto mercadológico é o "conjunto de instrumentos controláveis pelo gerente de marketing, através dos quais ele pode obter melhor ajustamento entre a oferta que sua empresa faz ao mercado e a demanda existente"[14].

A função principal do mix de marketing compreende as definições sobre o produto que abrange definição da oportunidade de lançamentos de produtos ou adequação desses à necessidades do consumidor; engloba também decisões de preço, tendo em vista gerar vantagem competitiva e retorno para a empresa; além de decisões de promoção, relativas aos investimentos em estratégias de comunicação e promoção de vendas; e as decisões de praça ou distribuição, que envolvem a escolha de canais de vendas que satisfaça as necessidades dos clientes[15].

$\mathrm{O}$ produto ou serviço é entendido como agente principal de comercialização, desenvolvido para atender as necessidades dos clientes, proporcionando benefícios [16]. Um produto Um produto pode ser definido como tudo o que uma pessoa recebe, seja favorável ou desfavorável, em uma relação de troca. Um produto pode ser uma mercadoria tangível, um serviço, uma ideia ou qualquer combinação dos três, e engloba não só a unidade física, mas garantia, serviços pós-venda, marca e imagem da empresa [17].

"O preço ajuda a dar valor às coisas e representa uma troca pelo esforço feito pela empresa vendedora através da alocação de recursos, capital e mão-de-obra dos produtos comercializados" [16]. O preço é o único elemento do composto de marketing capaz de gerar receita, sendo que os demais representam custos, e caracteriza-se também como um dos elementos mais flexíveis, pois ele pode ser alterado com rapidez [18].
"As empresas usam os canais de distribuição para poder atender em todos os mercados a todos os possíveis clientes ou consumidores" [19]. "A localização de um varejista é a chave de sua capacidade de atrair clientes. E os custosa para construir ou alugar instalações tem um grande impacto sobre os lucros dos varejistas. Portanto, a localização é uma das decisões mais importantes a serem tomadas"[20].

Umas das ferramentas mercadológicas mais importantes colocada aos varejistas é a promoção tendo a função de estimular a demanda relacionando serviços às necessidades e desejos de seu público-alvo. Ela sob qualquer forma tem como objetivo exercer influência. A promoção é a comunicação do varejista com o seu mercado-alvo e isto ocorre através de diversas técnicas [16]. A promoção é necessária para informar, persuadir e lembrar os consumidores que um produto existe e que os mesmos podem se beneficiar com a compra do produto [21].

\section{II.4 O SISTEMA FUZZY}

A teoria dos conjuntos fuzzy surgiu como ferramenta para responder a problemas relativos a informações vagas, imprecisas ou ambíguas, geralmente descritas em linguagem natural - termos qualitativos - para serem transcritas em linguagem numérica.

Em 1965 a teoria dos conjuntos fuzzy, ou teoria dos conjuntos difusos como também é conhecida, foi mencionada pela primeira vez pelo professor Lotfi Asker Zadeh, da Universidade de Berkeley, USA [22].

Reconhecido pela grande contribuição no Controle moderno, Zadeh observou, ainda em meados década de 60 , que os recursos tecnológicos disponíveis não eram capazes de automatizar as atividades relacionadas a problemas de natureza industrial, biológica ou química que compreendessem situações ambíguas, não processadas na lógica computacional. Buscando solucionar a problemática, L. A. Zadeh publicou em 1965 um artigo resumindo os conceitos dos conjuntos fuzzy, emergindo o assunto com a criação de sistemas fuzzy [23].

Diferentemente da lógica convencional, a lógica fuzzy suporta modos de raciocínio aproximados ao invés de exatos, em que permite o tratamento de informações qualitativas de uma forma rigorosa. Ela cumpre o papel de gerenciar imprecisões através da expressão de termos com um grau de pertinência, em um intervalo numérico $[0,1]$, que se tem a pertinência absoluta representada pelo valor 1 [24].

Um sistema fuzzy necessita de quatro elementos que são denominados fuzzificador e defuzzificador, base de regra e inferência fuzzy que estão conectados e podem ser representados conforme a Figura 1 [25].

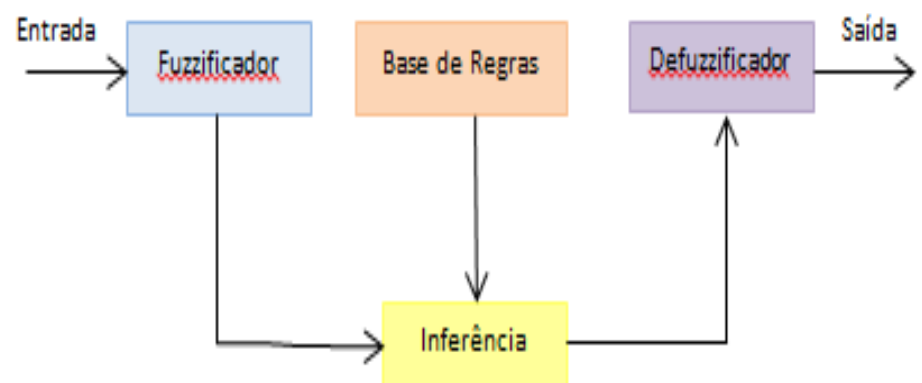

Figura 1: Sistemas Fuzzy.

Fonte: Adaptado [26].

O componente fuzzificador tem como principal função converter os valores reais de entrada em grau de pertinência a conjuntos fuzzy [26]. 
Ainda conforme a definição dos autores, a base de regras fuzzy trata de um conjunto de regras linguísticas "IF-THEN", sendo considerada a parte fundamental de um sistema fuzzy, uma vez que todos os outros componentes são utilizados para implementar as regras de modo eficiente e razoável.

O defuzzificador especifica um ponto na saída que melhor representa o conjunto fuzzy. Na escolha de um defuzzificador, os critérios de plausibilidade, simplicidade computacional e de continuidade devem ser considerados [22].

A inferência fuzzy, também definida pelos autores, é a etapa em que as proposições são definidas e depois são examinadas paralelamente. No processo de inferência fuzzy, os princípios da lógica são usados para combinar as regras fuzzy "IFTHEN" existentes na base de regras com os dados de entrada. $\mathrm{O}$ resultado final desta combinação é uma região fuzzy de saída que está relacionada com a saída do processo [27].

\section{MATERIAIS E MÉTODOS}

Pesquisa é definida "como o processo formal e sistemático de desenvolvimento do método científico cujo objetivo fundamental [...] é descobrir respostas para problemas mediante emprego de procedimentos científicos" [28].

O modelo adotado no sistema de previsão de demanda se baseou em simulação computacional como ferramenta, fundamentado com lógica fuzzy, como variáveis relevantes selecionadas para a análise teve-se Produto, Preço, Praça e Promoção.

As funções de pertinência que foram desenvolvidas para este sistema foram as varáveis já mencionadas; o intervalo numérico e o valor linguístico, conforme Tabela 1 a seguir:

Tabela 1: Funções de Pertinência do Sistema.

\begin{tabular}{|c|c|c|}
\hline Variáveis & Intervalo Numérico & Valor Linguístico \\
\hline \multicolumn{3}{|c|}{ ENTRADA } \\
\hline PRODUTO & \multirow{4}{*}[0-100]{} & \multirow{4}{*}{$\begin{array}{l}\text { (RUIM, BOM, } \\
\text { ÓTIMO) }\end{array}$} \\
\hline PREÇO & & \\
\hline PRAÇA & & \\
\hline PROMOÇÃO & & \\
\hline \multicolumn{3}{|c|}{ SAÍDA } \\
\hline $\begin{array}{l}\text { PREVISÃO } \\
\text { DE VENDA }\end{array}$ & {$[0-100]$} & $\begin{array}{l}\text { (MUITO RUIM, } \\
\text { RUIM, BOM, } \\
\text { MUITO BOM, } \\
\text { EXCELENTE) }\end{array}$ \\
\hline
\end{tabular}

Fonte: Autores, (2017).

Na Figura 2 é implementado um sistema de previsão de demanda na área de Interface Gráfica do usuário.

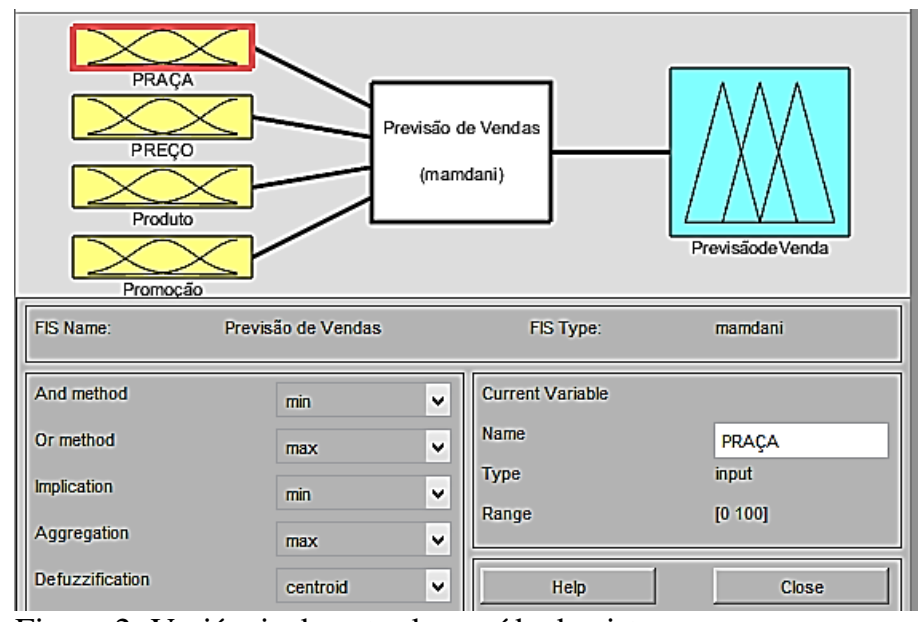

Figura 2: Variáveis de entrada e saída do sistema.

Fonte: Autores, (2017).
Quanto à descrição das variáveis, elas representam o conhecimento do especialista na inferência fuzzy, sendo denominados como variáveis de entrada e saída do sistema, correspondidos em termos linguísticos que representam modo de imprecisão. Dessa forma, as variáveis do sistema proposto são:

a) Produto - deve satisfazer a necessidade do consumidor e engloba características como qualidade, embalagem, design, garantia, entre outras, sendo uma variável de alta relevância. A fuzzificação dessa variável é trapezoidal nas extremidades e triangular na parte central do gráfico, conforme Figura 3.

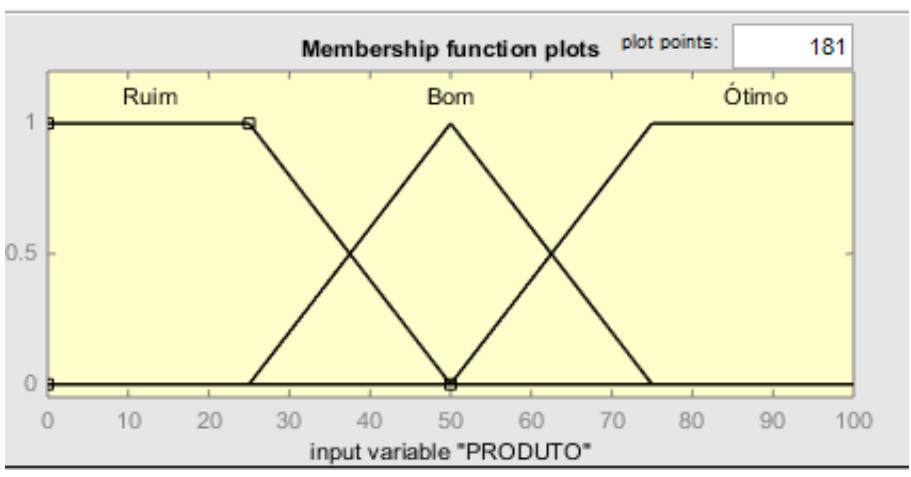

Figura 3: Variável Produto.

Fonte: Autores, (2017).

b) Preço - as estratégias que determinam o preço devem considerar os custos, a concorrência e o valor percebido pelos consumidores. A relevância dessa variável também é considerada alta na previsão da demanda com a fuzzificação também segundo os parâmetros da primeira variável descrita, conforme Figura 4.

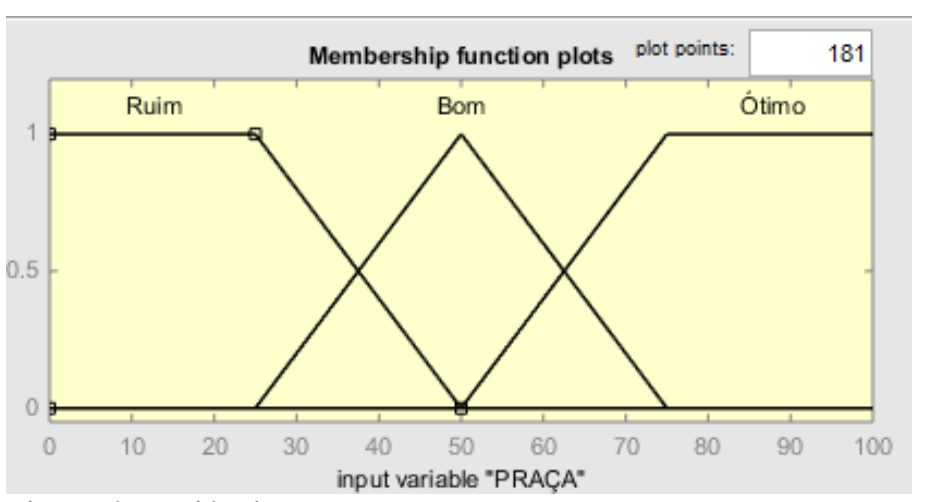

Figura 4: Variável Preço.

Fonte: Autores, (2017).

c) Praça - é o conjunto de organizações interdependentes envolvidas no processo de disponibilização do produto para o consumo. A relevância dessa variável é bastante considerável e a fuzzificação pode ser observada conforme Figura 5.

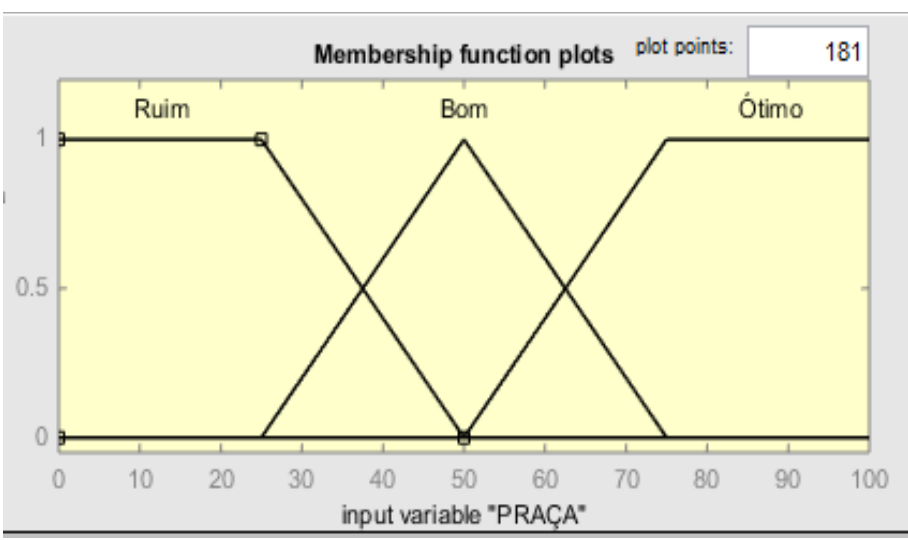

Figura 5: Variável Praça.

Fonte: Autores, (2017). 
d) Promoção - diz ao consumidor que o produto certo está disponível, com preço adequado e canal de distribuição adequado, também considerada uma variável imponente na previsão da demanda e tem sua fuzzificação disposta conforme Figura 6.

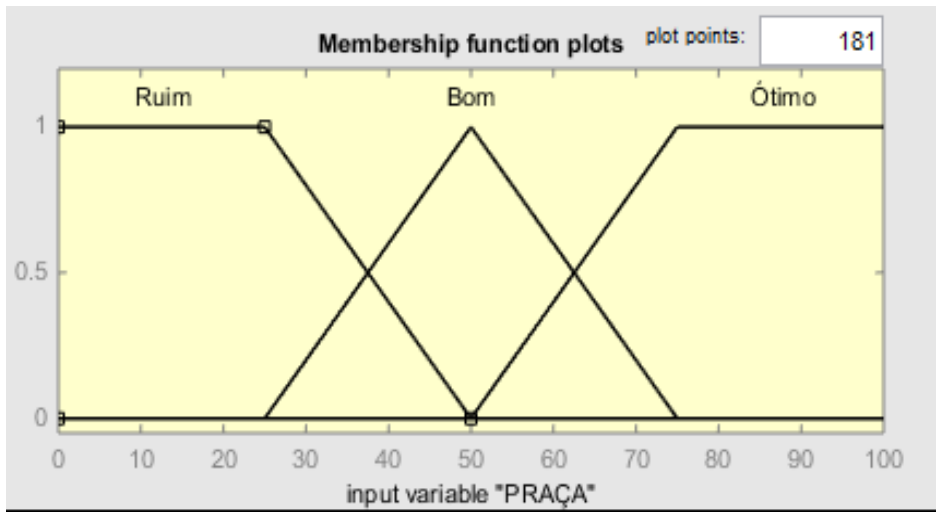

Figura 6: Variável Promoção.

Fonte: Autores, (2017).

e) Previsão de demanda - a associação das variáveis de entrada e saída, a qual tem a fuzzificação demonstrada na Figura 7.

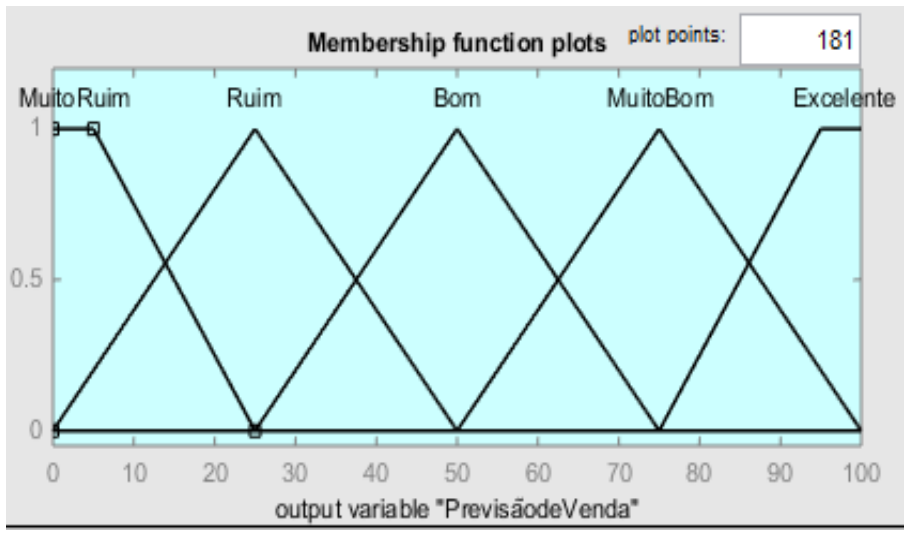

Figura 7: Variável de saída Previsão de Vendas.

Fonte: Autores, (2017).

A demonstração da principal Base de Regras de Inferência das variáveis linguísticas resultou em 81 combinações, aplicadas nesta solução fuzzy, onde parte dela poder observada na Figura 8.

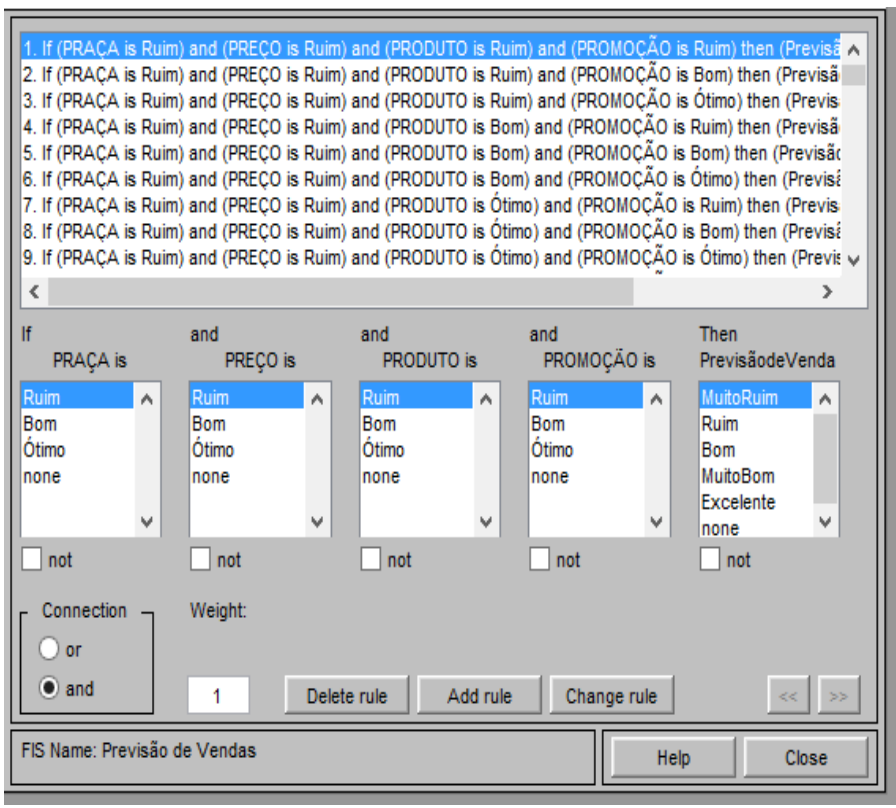

Figura 8: Regras de inferência das variáveis linguísticas.

Fonte: Autores, (2017).

\section{RESULTADOS E DISCUSSÕES}

Os dados dispostos no visualizador de regras facilitam a interpretação do processo de inferência fuzzy, onde também é possível demonstrar funções que refletem no resultado global do sistema.

Ao se variar os valores de entrada é possível avaliar as saídas do sistema proposto, obtendo um valor que permite uma correta análise da eficiência do método adotado para apoio na tomada de decisão no que tange a decisão de compra, observável na Figura 9.

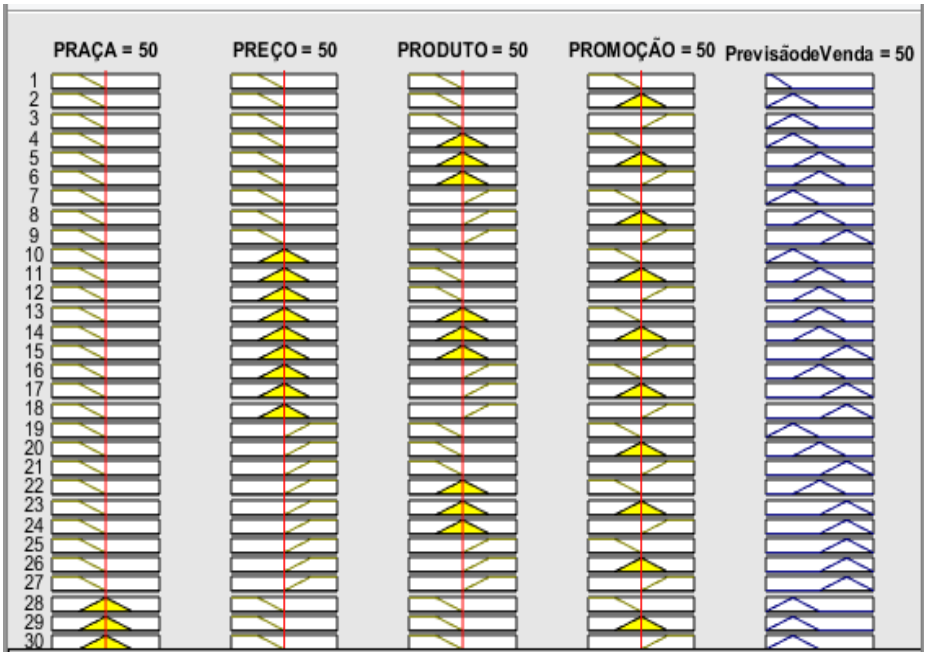

Figura 9: Resultado demonstrado a partir de inferências.

Fonte: Autores, (2017).

Ao se adotar valores hipotéticos os valores de entrada, considerando-os em percentuais, em que o valor adotado para a variável de entrada praça representa $20 \%$, para preço $70 \%$, para produto um valor de $90 \%$ e para promoção $15 \%$, resultando em uma previsão de venda correspondente a $69 \%$, ou seja, um cenário favorável para recompra.

Em uma segunda situação, ao se admitir o percentual de $10 \%$ para praça, $50 \%$ para preço, $10 \%$ para produto e $15 \%$ para a variável praça, resulta-se em uma saída equivalente a $25 \%$, que corresponde a um cenário pouco favorável para recompra.

Em uma terceira simulação, adotando $95 \%$ para variável praça, $90 \%$ para preço, $90 \%$ para produto e $95 \%$ para a variável praça, resultando em percentual de $91,7 \%$ para a previsão de venda, representando um cenário excelente para recompra.

\section{CONCLUSÃO}

A aplicação do modelo de inferência fuzzy mostrou-se eficiente e de baixo grau de dificuldade para utilização por especialistas no que tange a previsão da demanda de venda para controle de estoque, em que se desenvolveu um sistema de mensuração de recompra que melhor auxilie na tomada de decisão.

Dessa forma, confere-se ao estudo caráter científico, com contribuição relevante na mensuração da previsão da demanda de venda, possibilitando apoio à tomada de decisão que pode atribuir à organização um fator competitivo e maior lucratividade.

\section{AGRADECIMENTOS}

Ao Instituto de Tecnologia e Educação Galileo da Amazônia (ITEGAM) pelo apoio a essa pesquisa. 


\section{REFERÊNCIAS BIBLIOGRÁFICAS}

[1] N. Slack, S. Chamber, and R. Johnston, Administração de Produção, 2. ed. São Paulo: Atlas, 2009.

[2] H. Pozo, Administração de recursos materiais e patrimoniais. Uma abordagem logística. 5.ed. São Paulo: Atlas, 2008.

[3] M. A. P. Dias, Administração de Materiais: princípios, conceitos e gestão. 5. Ed. - 2. reimpr. - São Paulo: Atlas, 2006.: Atlas, 2006.

[4] P. G. Martins and P. R. C. Alt, Administração de Materiais e Recursos Patrimoniais. 3. ed. São Paulo: Saraiva, 2009.

[5] C. P. Chagas, S. Souza, and F. P. Simão, A Relevância do Sistema Informatizado para Controle de Estoques na Gestão Empresarial: Um Estudo de Caso, Quanta, 2009.

[6] P. F. Fleury, Conceito de logística integrada e supply chain management. Logística empresarial: a perspectiva brasileira. São Paulo: Atlas, 2000.

[7] J. J. Viana, Administração de Materiais. São Paulo: Atlas, 2000.

[8] F. J. C. L. Costa, Introdução à Administração de Materiais em sistemas informatizados. São Paulo: [s.n.], 2002.

[9] J. T. Luxhoj, J. O. Riis, and B. Stensballe, A hybrid econometric-neural network modeling approach for sales forecasting, Amsterdam International Journal of Production Economics. Elsevier Science B. V. n. 43, 1996.

[10] J. Armstrong, Standarts and practices forforecasting, In: armstrong, J. Principles of forecasting: a handbook for researchers and practitioners. ," Boston: Kluwer Academic Publishers, 2001.

[11] P. G. Francischini and F. A. Gurgel, Administração de materiais e do patrimônio. São Paulo: Pioneira, 2002.

[12] R. H. Ballou, Gerenciamento da cadeia desuprimentos/ logística empresarial. Tradução Raul Rubenich. - 5. Ed. - Porto Alegre: Bookman, 2006.

[13] P. Kotler, Marketing de serviços profissionais. 2. Ed. São Paulo: Manole, 2002.

[14] A. Rocha and C. Christensen, Marketing: teoria e prática no Brasil. São Paulo: Atlas, 1987.

[15] F. P. S. Gonçalves, O Impacto das Certificações de RSE sobre o Comportamento de Compra do Consumidor, In: encontro nacional da associação nacional dos programas de pósgraduação em administração," Rio de Janeito, ANPAD, 2008.

[16] A. L. Las Casas, Administração de Marketing: Conceitos, planejamento e aplicações à realidade brasileira. São Paulo: Atlas, 2006.

[17] C. W. J. Lamb, J. F. J. Hair, and C. McDaniel, Princípios de Marketing. São Paulo: Pioneira Thomson Learning, 2004.
[18] P. Kotler and K. L. Keller, Administração de Marketing. 12 Ed. São Paulo: Pearson - Prentice Hall Brasil, 2006.

[19] S. A. C. Fockink, "Plano de marketing do mercado e açougue Fockink," Santa Rosa, 2006.

[20] P. Kotler and G. Armstrong, Princípios de Marketing. 7 ed. Rio de Janeiro: Prentice - Hall do Brasil, 1998.

[21] R. E. Stevens, Planejamento de Marketing. São Paulo: Makron Books, 2001.

[22] C. C. Lee, Fuzzy Logic in Control Systems: Fuzzy Logic Controller, part I and II," IEEE Trans. on Systems, Man and Cybernetics, vol. 20, pp 404-435, 1990.

[23] E. RUSS, P. SIMPSON, and R. DOBBINS, Computational Intelligence PC tool. London: AP Professional, 1996.

[24] P. Albertos, "Fuzzy Controllers - AI Techniques in Control " Pergamon Press, 1992.

[25] E. Cox, The Fuzzy System Handbook: a Practitioner's Guide to Building, Using and Maintaining Fuzzy Systems, 1994.

[26] I. S. Shaw and M. G. C. e. M. F. Simões, "Controle e Modelagem Fuzzy.," São Paulo.Edgard Blücher; FAPESP, 1999.

[27] R. Yager, S. Ovchinnikov, R. M. Tong, and N. H. T., Fuzzy Sets and Applications: Wiley Interscience, New York, 1987.

[28] A. C. Gil, Métodos e técnicas de pesquisa social. São Paulo: Atlas, 1999. 